\title{
Fine-Scale Tracking of Marine Turtles Using GPS-Argos PTTs
}

\author{
Tohya Yasuda* and Nobuaki Arai \\ Department of Social Informatics, Graduate school of Informatics, Kyoto University, \\ Yoshidahonmachi, Sakyo-ku, Kyoto 606-8501, Japan
}

\begin{abstract}
High-accuracy location data of wildlife telemetry using conventional satellite location systems are difficult to obtain. However, such data are necessary to clarify the nature of movements and home range sizes of animals. In order to measure the high-accuracy location data, we developed new GPSArgos Platform Terminal Transmitters (PTTs) which transmit both the conventional location and GPS location simultaneously. Two experiments, one in an artificial rearing pond and the other in the open sea, were performed. First, two hawksbill turtles were tracked with the PTTs in a 5 ha breeding pond in Thailand. Their home ranges using both data were calculated and found to be 2.96 ha and 0.93 ha by the GPS data, and 156,740 ha and 184,478 ha by a conventional data. Secondly, a female green turtle attached with the GPS-Argos was released from the coast of Pangnga Province, Thailand. There was a relationship between depth and speed of travel based on the GPS data. The data from the PTT showed that the turtle moved south along the coastline at the depth of less than $20 \mathrm{~m}$ for 5 days, and then stayed at a depth of less than $10 \mathrm{~m}$ for 4 days. However, we could not find any clear relationship using conventional data. Only a meandering movement at a variety of depths was observed. The results of the two experiments indicated the PTTs have an enormous potential for enhancing our understanding of fine-scale movement patterns and home ranges of marine turtles.
\end{abstract}

Key words: GPS, Argos system, satellite tracking, marine turtles, home range

\section{INTRODUCTION}

Wildlife telemetry using the Argos system has been widely used by biologists to track movements of marine and terrestrial vertebrates. Many features of marine turtle behaviour, such as long-distance movement, have been discovered by using the Argos system (e.g. Hatase et al., 2002; Luschi et al., 2003a). The next step of such studies is to examine the interaction between turtle movement and environmental factors, including oceanographic data which are developed by mathematical modeling and remote-sensing technology.

However, there are two problems with the conventional satellite tracking data. First, the system cannot track underwater movements of animals. Recently, the satellite relayed data logger (SRDL; http://smub.st-and.ac.uk/InstrumentationF.htm/srdls.htm) which can record multiple types of data, such as dive depth and dive duration, has overcome this disadvantage, and the instrument has become useful for examining the underwater behavior of marine animals during movements (e.g. Hays et al., 2004). The second problem is the lack of location accuracy of conventional satellite tracking. Generally, almost all the tracking data are inaccurate for marine animal satellite tracking. For long-distance movement and the general pattern of the movement, the accuracy of locations is unimportant. However, for smallscale movement location accuracy of tracking data is likely to become an important issue (Hays et al., 2001a). But the problem is surprisingly still unsolved.

The typical accuracy of location of the conventional Argos system can be anywhere between $100 \mathrm{~m}$ and 4000 $m$ (Keating, 1994; Britten et al., 1999) which is not good enough to understand the details of wildlife movement and to make a convincing argument for or against particular con-

Table 1. The transmitter T-2071RF module

\begin{tabular}{l|c}
\hline Output power & $1 \mathrm{~W}$ \\
Operation days & 25 days (continuation floating) \\
GPS interval & Max 4 times/day (6h/day) \\
Repetition period & $45 \mathrm{~s}$ \\
Antenna & Whip antenna \\
Data & GPS UTC Time \\
& GPS Location \\
& Surface time counter \\
& Battery voltage \\
\hline
\end{tabular}

$\begin{aligned} & \text { * Corresponding author. Phone: }+81-75-753-3296 ; \\ & \text { Fax : +81-75-753-3133; } \\ & \text { E-mail: tohya @ bre.soc.i.kyoto-u.ac.jp }\end{aligned}$ 
servation methods. Therefore, it is necessary to develop a new generation of satellite-linked instruments from which fine-scale movements can be reconstructed. We adapted the Global Positioning System (GPS) for this purpose.
Although the GPS has been used in terrestrial applications, there are few studies on marine animals using this system (Jay and Garner, 2002; Ryan et al., 2004). Therefore, we developed and applied the GPS-Argos Platform Terminal
A

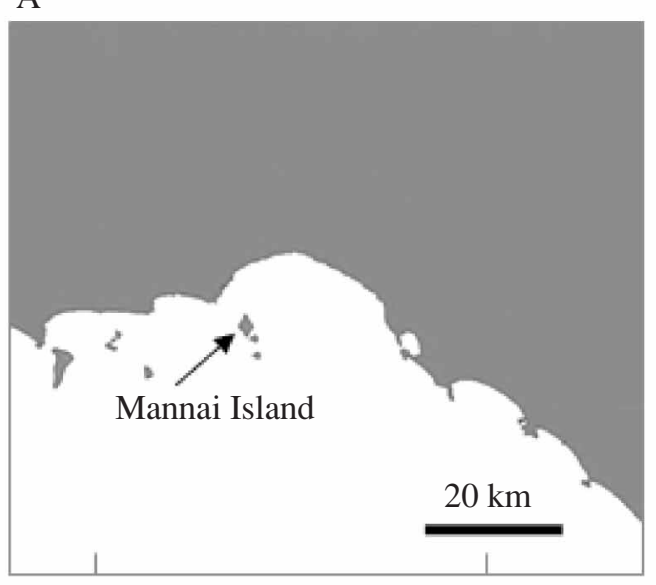

$101^{\circ} 30^{\prime} \mathrm{E}$

$\mathrm{C}$

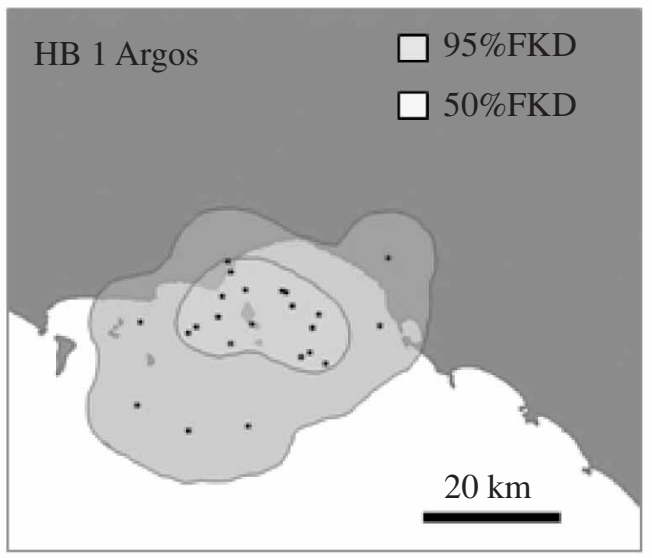

E

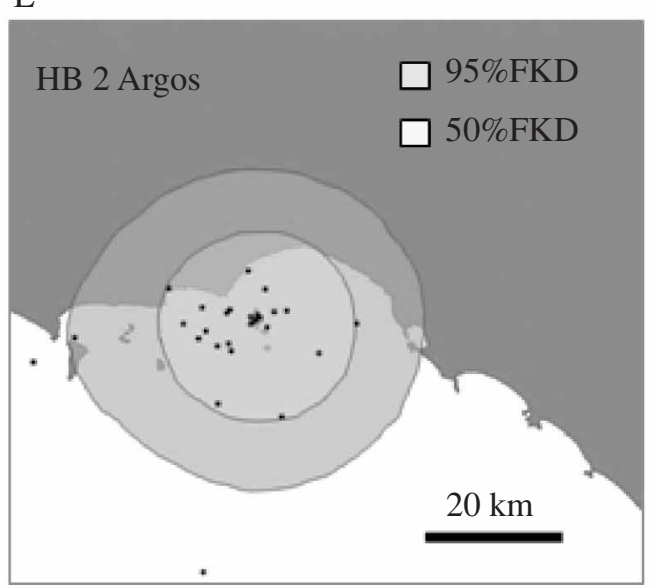

B

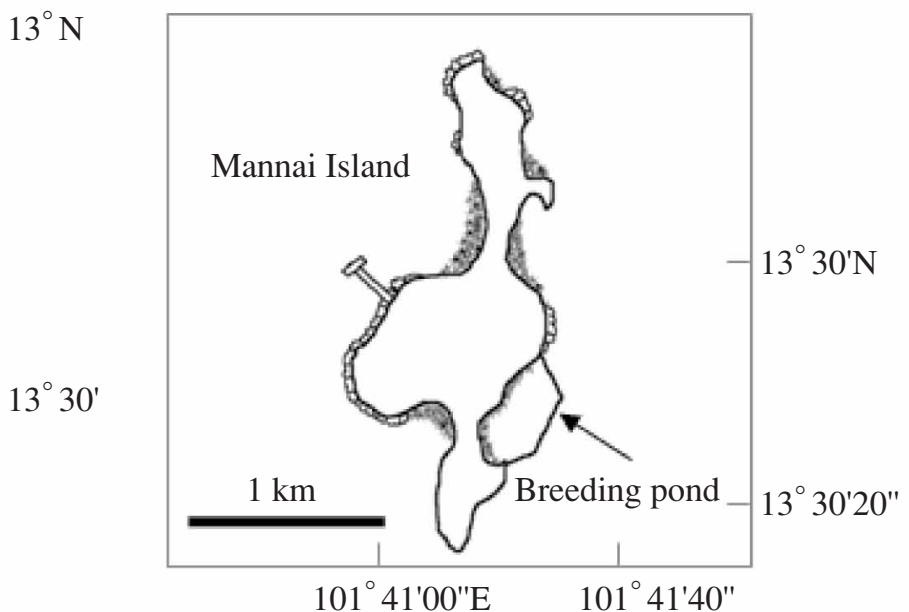

$\mathrm{D}$
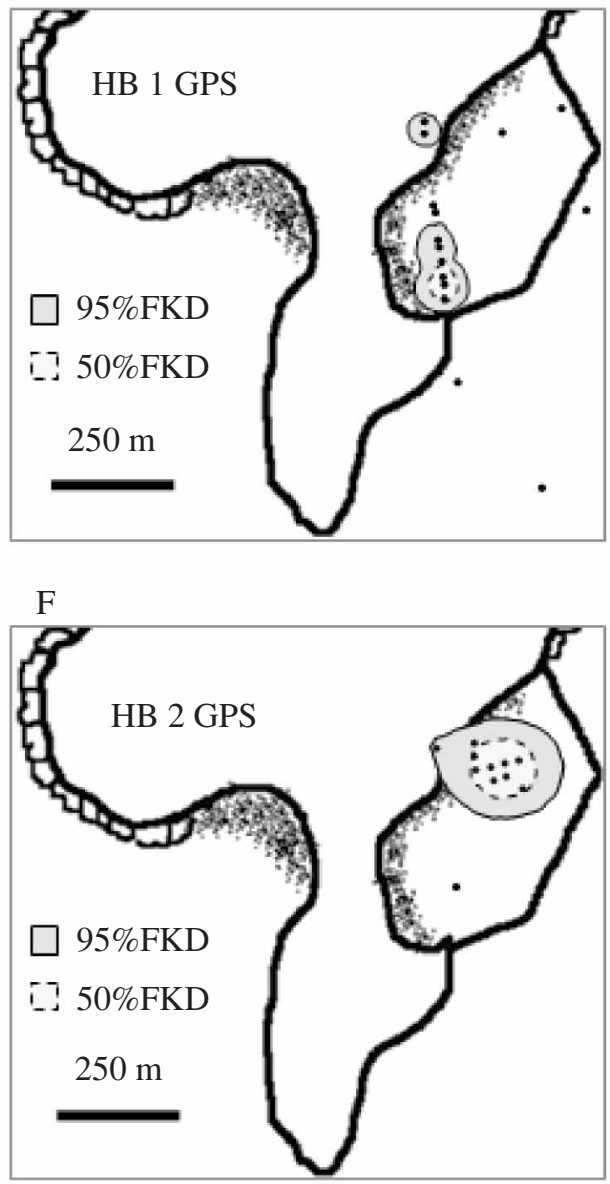

Fig. 1. A map of the study site and the home ranges for two hawksbill turtles in a breeding pool with 5 ha. (A) A map of Gulf of Thailand. B: A map of Mannai Island. (C) A map of home range for HB1 estimated from conventional data. (D) A map of home range for HB1 estimated using GPS data. (E) A home range map for HB2 estimated from the conventional data. (F) A map of home range for HB2 estimated using GPS data. (FKD: Fixed kernel density). 
Transmitters (PTTs) (Arai and Ono, 2002) to track marine turtles on a fine-scale. The GPS-Argos PTTs transmit both the conventional location data and the GPS location data simultaneously. Therefore, it is possible to compare both location data sets and evaluate the efficiency of PTTs. This is the first report of the results of two experiments conducted under both artificial and natural conditions utilizing GPS tracking.

\section{MATERIALS AND METHODS}

The GPS-Argos transmitters (Arai and Ono, 2002) were used to reconstruct the movements and to estimate the home ranges of marine turtles. The transmitter (T-2071, TOYOCOM Co. Ltd., Tokyo, Japan; Table 1) was installed with a GPS receiver (CCA-452J, Japan Radio Co., Ltd, Tokyo, Japan) and a GPS controller. Locations were calculated using an onboard processing unit after receiving data from more than four GPS satellites. When the GPS receiver calculated a new location, the previous location was overridden.

The transmitter's location was also estimated by the conventional Argos system which involves transmitting radio signals (401.650 MHz) at a predetermined interval (typically 45-90 seconds for wildlife tracking) to either of two polar-orbiting NOAA satellites. The location of a transmitter was estimated using detected Doppler shifts. The GPS-Argos PTTs transmitted radio signals to the NOAA satellites with the GPS position data which was obtained before transmitting. The transmitters turned on when the conductivity sensor detected a dry condition in order to save the battery charge because radio signals cannot be sent (or received) to (or from) the satellites in water.

Two experiments were conducted in 2003 and 2004 under artificial and natural conditions in Thailand. Simple filtering processes were generally used for analysis of satellite tracking data in order to remove poor-quality locations. We used $5 \mathrm{~km} / \mathrm{h}$ as the upper threshold to include speeds in subsequent analysis (e.g. Luschi et al., 1998). The speed of travel for the turtle was calculated from successive locations.

\section{Experiment 1}

Experiment 1 was conducted in an outside breeding pond at the sea turtle conservation station on Mannai Island, Thailand, January 7, 2004 (Fig. 1A). The breeding pond has an area of approximately 5 ha and is $3 \mathrm{~m}$ deep. Two prototype GPS-Argos transmitters were quickly attached on carapaces of two hawksbill turtles (Eretmochelys imbricata) using epoxy resin. The turtles were released from the sand beach adjacent to the breeding pond. Curved carapace lengths of the hawksbill turtles were $80.3 \mathrm{~cm}$ and $79.0 \mathrm{~cm}$. The transmitters used in the experiment were less than $144 \mathrm{~mm}$ in diameter, less than $67.5 \mathrm{~mm}$ in height and $1.4 \mathrm{~kg}$ in weight in air. The outer frame of the breeding pond was measured with a portable GPS receiver (GPS 3, GARMIN Co. Ltd, Olathe, KS, USA).

Home range areas were estimated by the fixed kernel density method (Worton, 1987; Worton, 1989) using the animal movement

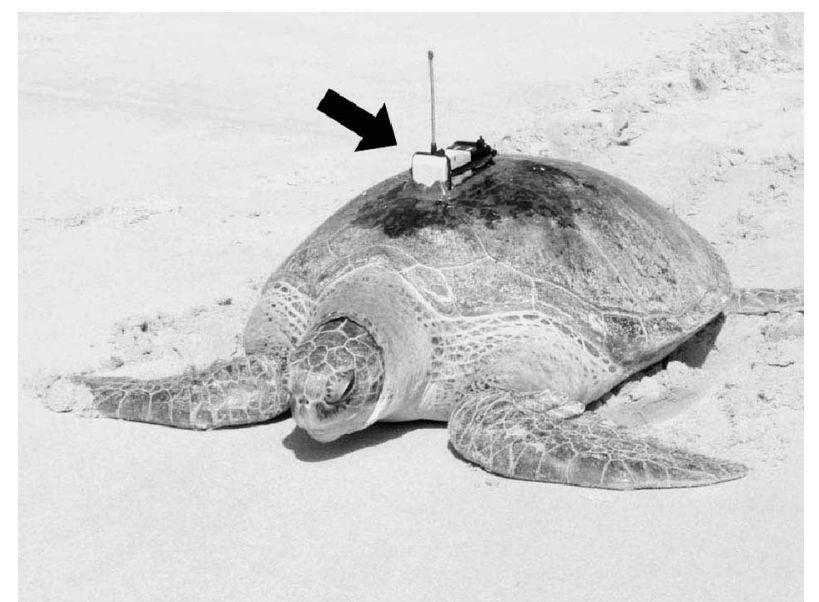

Fig. 2. The female green turtle (Chelonia mydas) equipped with the GPS-Argos transmitter.

(USGS; http://www.absc.usgs.gov/glba/gistools/) for the ArcView version 3.1 geographic information system (GIS) software (ESRI; http://www.esri.com/software/arcview) in order to examine the distribution of the GPS and Argos locations during the monitoring period. Fixed kernel home ranges were calculated with least square cross validation as a band width (termed a smoothing parameter; Silverman, 1986). A 95\% utilization distribution was used to estimate the overall home range, whereas a $50 \%$ utilization distribution was used to establish the core area.

\section{Experiment 2}

Experiment 2 was conducted under natural conditions in January 2003. The improved prototype GPS-Argos transmitter was attached to the carapace of an adult female green turtle (Chelonia mydas) using epoxy resin (Fig. 2). The turtle was rescued from bycatch. The transmitter, smaller than the one used in the experiment 1 , was ca. $171 \mathrm{~mm}$ in length, ca. $60 \mathrm{~mm}$ in width, ca. $57 \mathrm{~mm}$ in height and weighs ca. $1 \mathrm{~kg}$ in air. The curved carapace length and curved carapace width of the turtle were $103 \mathrm{~cm}$ and $94 \mathrm{~cm}$, respectively. To save the battery of the transmitter, a duty cycle was set up $6 \mathrm{~h}$-on/ $6 \mathrm{~h}$-off for the GPS receiver and 3 days-on/ 3 daysoff for the transmitter. On January 6, 2004, the turtle equipped with the transmitter was released off the coast of Phangnga Province, Thailand $\left(8^{\circ} 25^{\prime} 155 \mathrm{~N} ; 98^{\circ} 14^{\prime} 525 \mathrm{E}\right)$ and monitored via the Argos system.

\section{RESULTS}

\section{Experiment 1}

Two hawksbill turtles were monitored via the Argos system from January 7, 2003 to January 18, 2003. The results are summarized in Table 2. The numbers of all Argos locations of HB1 and HB2 was 124 and 134, respectively, while

Table 2. The summary of results of the preliminaliry GPS-Argos tracking for two hawksbill turtles at the breeding pond with 5 ha in the sea turtle conservation station in Mannai Island, Thailand.

\begin{tabular}{ccccccccccccc}
\hline Turtle & CCL & $\begin{array}{c}\text { Tracking } \\
\text { period }\end{array}$ & LC 3 & LC 2 & LC 1 & LC 0 & LC A & LC B & LC Z & Total & No. of GPS \\
& $(\mathrm{cm})$ & (days) & LC of errors) \\
\hline HB 1 & 80.8 & 12 & $1(0)$ & $1(0)$ & $1(0)$ & $14(6)$ & $10(6)$ & $31(20)$ & $57(57)$ & $115(89)$ & $51(11)$ \\
HB 2 & 79.0 & 12 & $2(0)$ & $5(0)$ & $9(0)$ & $9(2)$ & $13(7)$ & $28(16)$ & $46(46)$ & $112(71)$ & $75(18)$ \\
\hline
\end{tabular}


the number of filtered Argos locations was 26 and 41 locations, respectively. The proportion of location classes for two turtles was $5 \%$ for $\operatorname{LC} 3,9 \%$ for $\operatorname{LC} 2,15 \%$ for $\operatorname{LC} 1,22 \%$ for LC $0,15 \%$ for LC A, 34\% for LC B and $0 \%$ for LC Z, respectively. The numbers of all GPS locations of HB1 and HB2 was 51 and 75, respectively, while the numbers of filtered GPS locations was 40 and 57, respectively.

Although two hawksbill turtles were in the breeding pond during the monitoring period, the filtered Argos locations were scattered around the Mannai Island (Figs. 1C and E). In contrast, the GPS locations indicated they were in the pond (Figs. 1D and F). Table 3 shows the results of the home range estimates for the hawksbill turtles during the monitoring period. Although the area of the breeding pond was approximately 5 ha, the fixed kernel home range areas estimated by the filtered Argos location showed unrealistic results $(156,740$ ha for $\mathrm{HB} 1,184,478$ ha for HB2). In contrast, the home ranges by the GPS locations were 2.96 ha for HB1 and 0.93 ha for HB2.

\section{Experiment 2}

Table 4 summarizes the locations from the GPS and

Table 3. The summary of results of the fixed kernel home range estimation for hawksbill turtles in the breeding pond with 5 ha.

\begin{tabular}{cccc}
\hline Turtle & $\begin{array}{l}\text { No. of locations } \\
\text { (Argos, GPS) }\end{array}$ & $\begin{array}{l}\text { Home range area } \\
\text { of Argos (ha) }\end{array}$ & $\begin{array}{l}\text { Home range area } \\
\text { of GPS (ha) }\end{array}$ \\
\hline HB 1 & 26,40 & 156,740 & 2.96 \\
HB 2 & 41,57 & 184,478 & 0.93 \\
\hline
\end{tabular}

Table 4. The summary of location data obtained from GPS and Argossystem for green turtles released from Phanga, Thailand.

\begin{tabular}{|c|c|c|c|c|c|}
\hline \multicolumn{6}{|c|}{ GPS locations } \\
\hline Date & Time & Longtitude & Latitude & $\begin{array}{l}\text { Speed of travelling } \\
(\mathrm{km} / \mathrm{s})\end{array}$ & \\
\hline $2004 / 1 / 6$ & $4: 49$ & 8.419 & 98.242 & - & \\
\hline $2004 / 1 / 6$ & $10: 50$ & 8.3835 & 98.222 & 0.748 & \\
\hline $2004 / 1 / 6$ & 17:06 & 8.3375 & 98.228 & 0.819 & \\
\hline $2004 / 1 / 7$ & $23: 34$ & 8.2931 & 98.2438 & 0.171 & \\
\hline $2004 / 1 / 10$ & $20: 03$ & 8.304 & 98.26 & 0.031 & \\
\hline $2004 / 1 / 14$ & 19:46 & 8.3075 & 98.2596 & 0.004 & \\
\hline \multicolumn{6}{|c|}{ Argos locations } \\
\hline Date & Time & Longtitude & Latitude & $\begin{array}{l}\text { Speed of travelling } \\
(\mathrm{km} / \mathrm{s})\end{array}$ & LC \\
\hline $2004 / 1 / 6$ & $5: 29$ & 8.423 & 98.237 & - & 1 \\
\hline $2004 / 1 / 6$ & 7:07 & 8.419 & 98.24 & 0.338 & 2 \\
\hline $2004 / 1 / 6$ & $8: 45$ & 8.405 & 98.232 & 1.091 & 1 \\
\hline $2004 / 1 / 6$ & 9:04 & 8.408 & 98.146 & 29.927 & A \\
\hline $2004 / 1 / 6$ & $11: 32$ & 8.368 & 98.229 & 4.117 & A \\
\hline $2004 / 1 / 6$ & $12: 23$ & 8.279 & 98.139 & 16.436 & z \\
\hline $2004 / 1 / 6$ & 13:53 & 8.365 & 98.29 & 12.774 & A \\
\hline $2004 / 1 / 6$ & $16: 36$ & 8.34 & 98.21 & 3.399 & 0 \\
\hline $2004 / 1 / 6$ & $17: 28$ & 8.349 & 98.239 & 3.860 & B \\
\hline $2004 / 1 / 6$ & $21: 25$ & 8.284 & 98.232 & 1.830 & 0 \\
\hline $2004 / 1 / 10$ & $20: 37$ & 8.296 & 98.26 & 0.035 & 2 \\
\hline $2004 / 1 / 14$ & 19:55 & 8.301 & 98.289 & 0.034 & 1 \\
\hline 2004/1/14 & $21: 52$ & 8.522 & 98.083 & 17.101 & z \\
\hline $2004 / 1 / 14$ & $22: 38$ & 8.297 & 98.258 & 41.054 & 2 \\
\hline
\end{tabular}

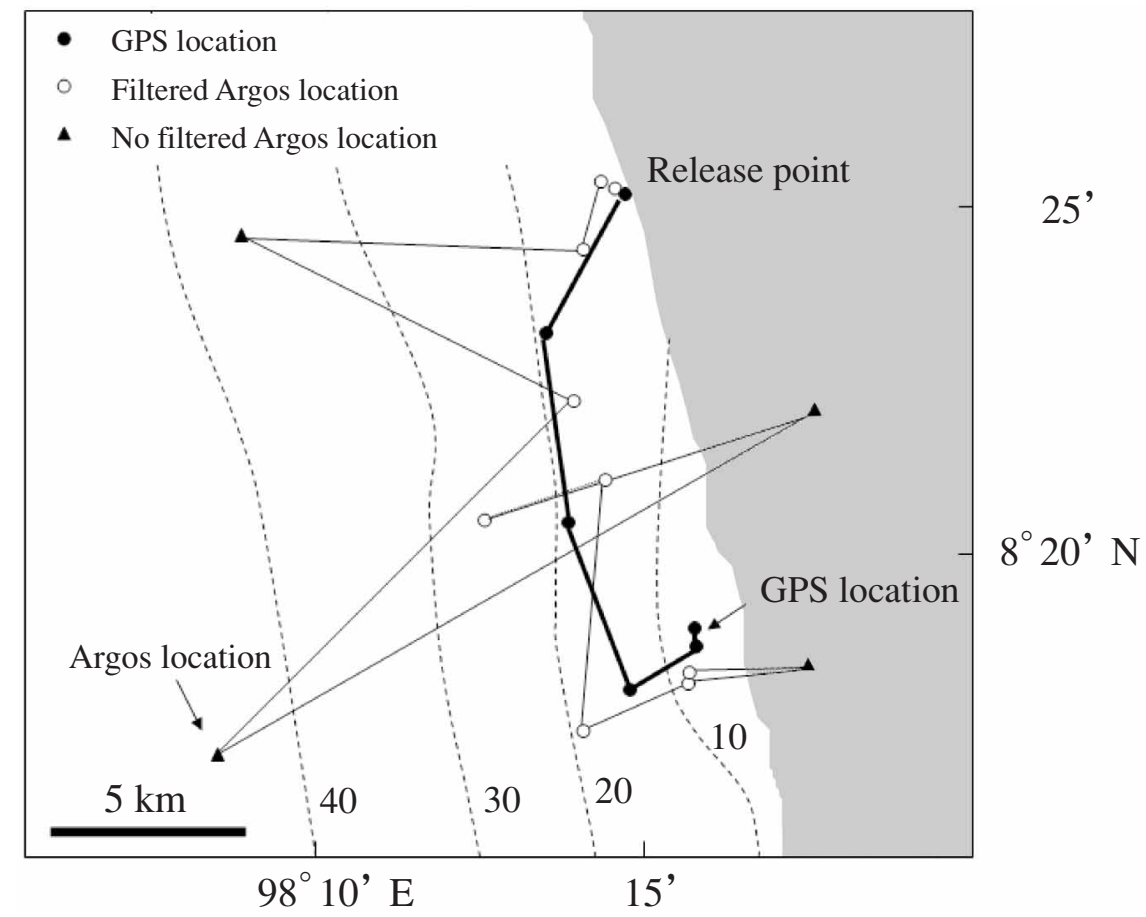

Fig. 3. Migration routes reconstructed from GPS locations and Argos locations for the female green turtle with the GPS-Argos transmitter. The turtle released from the coast of Phangnga Province, Thailand. Black circles, white circle and black triangles indicate the GPS locations, the filtered Argos locations and the no filtered Argos locations, respectively. Broken lines show isobaths of water depth. A black bar shows $5 \mathrm{~km}$. 
the Argos systems. The turtle was tracked from January 6 to January 14 . On January 14 , signals from the transmitter were disrupted by unknown problems. The total number of locations was 6 for the GPS and 14 for the Argos system. The proportion of rich-accuracy locations for the Argos system (LC 3, 2 and 1) was 43\% (6/14). Fig. 2 shows movements reconstructed from the GPS locations and the Argos locations for the green turtle equipped with the GPS-Argos transmitter. The GPS locations clearly showed that the turtle swam southward at a speed of 0.748 to $0.819 \mathrm{~km} / \mathrm{h}$ at the depth of less than $20 \mathrm{~m}$ for 5 days and maintained a speed ranging from 0.004 to $0.171 \mathrm{~km} / \mathrm{h}$ at ca. $10 \mathrm{~m}$ for 4 days. In contrast, the Argos locations showed a meandering movement with the speed ranging from 0.034 to $29.927 \mathrm{~km} / \mathrm{h}$ at various depths (Fig. 3). The speed of travel calculated from successive locations for GPS gradually changed, while that for Argos showed an unrealistic change (Table 4). The mean speed shown by the GPS as $0.36 \pm 0.40$ (S.D.) $\mathrm{km} / \mathrm{h}$, while that for Argos was $4.43 \pm 8.59$ (S.D.) $\mathrm{km} / \mathrm{h}$.

\section{DISCUSSION}

\section{Home range estimate}

Home range analysis is a very effective method for both an understanding of use of habitat and the establishment of conservation measures (e.g. a marine protect area) for marine turtles. However, we have to interpret the estimated home range with caution because an overestimate or an underestimate of home ranges may cause conservation efforts to fail. Since little research has been conducted on the home ranges of marine turtles, their biological features remain largely unknown. Mendonca (1983) reported that green turtle size affects the home range by tracking small juveniles and larger sub-adults. However, Seminoff et al. (2002) reported that there was no significant size effect on home range area. Also, substantially different home range sizes of green turtles have been reported (22 to 3908 ha; Mendonca, 1983; Renaud et al., 1995; Whiting and Miller, 1998; Seminoff et al., 2002). Home ranges of loggerhead turtles (Caretta caretta) tracked by satellite telemetry were reported to be from 95,400 to $2,883,300$ ha (Renaud and Carpenter, 1994). Therefore it is not possible to compare the results of these studies since they were made with different species in different habitats and for various durations and foraging ecologies. The method used to establish home range sizes affects the results. Some researchers used radio and sonic telemetry to track movements of green turtles (Mendonca, 1983; Renaud et al., 1995; Whiting and Miller, 1998; Seminoff et al., 2002). These methods disable continuous tracking, therefore the results may be biased depending on the degree of effort, the field conditions, the maximum radius of signal reception of the instruments as well as other variables. Satellite tracking can reduce these problems although it may overestimate home range sizes (Fig. 1C and E) because of location inaccuracies. Our results from experiment 1 using GPS locations estimated true home range sizes (Figs. 1D and F). Using the GPSArgos PTTs, we can investigate the mechanisms of the home ranges of marine turtles and correlate home range size with environmental factors because they are estimated on a fine-scale and reduce factors that cause bias of the data.

\section{Migration tracking}

In experiment 2, a free-ranging green turtle was tracked by the GPS-Argos transmitter. In spite of the short monitoring period, we found a relationship between depth and speed of travel. Locations and speed obtained from GPS were divided into two periods; a traveling period at a depth of less than $20 \mathrm{~m}$ (from 7 January to 10 January) and a staying period in less than $10 \mathrm{~m}$ of water (from 10 January to 14 January) (Fig. 3 and Table 4). GPS locations were obtained only in 7 locations, but the results seemed to represent a real biological signal from the green turtle. Dive durations of green turtles are short (5 $\mathrm{min}$ to $10 \mathrm{~min}$ ) and frequent during travel, compared to when turtles are resting at shallow waters where dive durations of $30-40 \mathrm{~min}$ are common (Hays et al., 1999). There is little data about the behavior of the turtles during the resting period compared to the traveling period, which is likely due to changes in the diving behavior of the green turtle; long dive duration decreases the number of uplinks of the transmitter.

High-accuracy locations enable us to examine the nature of the movement of marine turtles. Hays et al. (2001a) described systematic changes from satellite tracking of speed of travel of green turtles that moved from Ascension Island to Brazil. However, the small number of locations limits our ability to examine those in this study. Why communication from the transmitter was stopped on January 14 is not known. Locations from January 10 to January 14 suggest that the turtle stayed in the area at depths of less than $10 \mathrm{~m}$ (Fig. 2). There were many species of sea grasses in this area which are fed upon by a variety of animals including green turtles. Probably, the turtle was accidentally caught by a local fishery, using gill or drift nets.

\section{Efficiency of the GPS-Argos transmitter}

This study shows that the GPS-Argos has an enormous potential for increasing our understanding of the home range and the fine-scale movement patterns of marine turtles. Satellite tracking by the Argos system has enabled us to determine gross movement patterns of marine turtles, but it is difficult to understand the details of movement from the data obtained from the conventional satellite telemetry because of the lack of location accuracy.

The Argos system classified the accuracy of each location (LC 3, 2, 1, 0, A, B and Z), and Argos (1996) states that the estimate accuracy is $<150 \mathrm{~m}$ for LC 3, between 150 and 350 for 2, between 350 and $1000 \mathrm{~m}$ for LC 1, > $1000 \mathrm{~m}$ for LC 0 and no limits of accuracy for the remaining three classes (LC A, B and Z). Of these, LC 3, 2, 1 and 0 may be provided only when at least four uplinks are received on an 
overpass. LC A is provided when a location is determined from three uplinks; and LC B when a location is determined from two uplinks. In studies of aquatic divers, almost all tracking data showed poor-accuracy locations (Table 2) because uplinks from a transmitter should be sent when the transmitter was not only at the surface but also at each Argos satellite overpass. Therefore, there was a limited number of uplinks for the Argos system.

In this study the results showed that the GPS-Argos transmitters were useful in reconstructing fine-scale movements and to estimate home ranges of marine turtles (Figs. 1 and 3). Unlike the Argos system, the GPS receives signals from satellites and calculates the position of the subject using the signals from more than four satellites. The transmitters are onboard a constellation of 24 satellites and the system provides nearly continuous positioning capability worldwide. This system was designed to call for four satellites to be in view of any position on the earth's surface at any one time. GPS horizontal estimates are expected to fall within $100 \mathrm{~m}$ (Selective Availability activated) or $5 \mathrm{~m}$ (Selective Availability deactivated as in this study) of their true location 95\% of the time (Rodgers et al., 1996; Dussault et al., 2001).

Recently, GPS has become available for wildlife telemetry (Arai and Ono, 2002; Jay and Garner, 2002; Ryan et al., 2004). Ryan et al. (2004) reconstructed a foraging trip of African penguins (Spheniscus demersus) on a fine-scale using GPS data loggers. However, recovery of GPS loggers to obtain the data is problematical(Ryan et al., 2004). Therefore, data loggers were mainly deployed on specific animals that returned to a particular position after a trip (e.g. penguins, female turtles during inter-nesting period, etc.). In contrast, the Argos system was an effective link in relaying the GPS data because the system does not need to be recovered to obtain the data. An added advantage of using the Argos system for data retrieval was that the system was capable of producing location estimates of its own, albeit usually much less accurate than those from GPS (Jay and Garner, 2002). Using the locations obtained from both of these two systems together an animal's movement is more likely to be predictable (Table 4 and Fig. 3).

Jay and Garner (2002) described the main disadvantages of the Argos satellite-linked retrieval system. The number of GPS positions that can be downloaded is limited by the capacity of the sensor data (maximum 256-bit) in an Argos transmission. Therefore, if the number of GPS positions exceeded the number of the Argos uplinks, then some GPS data would be lost. An added disadvantage of GPSArgos is the size and mass of the device. Although the GPSArgos is smaller in experiment 2, the transmitter has to be much smaller in size and mass to apply to a wider variety of animals.

The World Conservation Union (IUCN) lists the global population of some species of marine turtles as 'endangered' (Hilton-Taylor, 2000), and now many marine turtle populations are known to have declined due to human activ- ities. Adult turtles, especially, are experiencing high levels of fishery by-catch, and the need for increased protection is heightened (Hays et al., 2003). Recently, advanced fishing gear (e.g. the Turtle Exclusive Device: TED) has been developed to avoid by-catch. However, this gear often cannot be applied in specific regions (e.g. Southeast Asia) because almost all the fisheries in these regions are cottage fisheries. In contrast, there are few ecological approaches that allow for cohabitation with human activities (e.g. legitimate marine protected area) taking into consideration the behavior of marine turtles. To design a cohabitation plan between marine turtles and human activities, we have to first examine the relationship between turtle behavior and environmental factors. Although oceanographic data have become available, thanks to remote-sensing technology (e.g. ocean current (sea surface height), primary production (sea color), sea grass and algae beds (satellite image and chlorophyll)), there are few integrative studies using these techniques (Polovina et al., 2000; Hays et al., 2001b; Horrocks et al., 2001; Luschi et al., 2003b; Polovina et al., 2004). The reconstruction of movement and estimation of home range on a fine-scale will play an important role in analysis of the relationship between marine turtles and oceanographic data. Then, the GPS-Argos will demonstrate its potential.

\section{ACKNOWLEDGMENTS}

We wish to thank K. Ono and K. Mizuno (KENWOOD Co. Ltd., Tokyo, Japan) for their cooperation in the development of the GPSArgos PTTs. M. Charuchinda and K. Kittiwattanawong supported the field studies in Thailand. L.B. Liddle helped to improve the manuscript. We also thank two anonymous reviewers for their constructive comments. This work was conducted under the permission of the National Research Council in Thailand (NRCT). This work was partly supported by a Grant-in-Aid for Scientific Research of the Japan Society for the Promotion of Science (JSPS)(grant no. 14560149) and a grant from the Research Fellowships of JSPS for Young Scientists to T.Y.

\section{REFERENCES}

Arai N, Ono K (2002) Development of a GPS-Argos PTT for marine animal tracking. ARGOS Forum 59: 19

Argos (1996) User's manual. CLS/Service Argos, Toulouse

Britten MW, Kennedy PL, Baker A (1999) Performance and accuracy evaluation of small satellite transmitters. J Wildl Manage 63: $1349-1358$

Dussault C, Courtois R, Ouellet J-P, Huot J (2001) Influence of satellite geometry and differencial correction on GPS location accuracy. Wildl Soc Bull 29: 171-179

Hatase H, Matsuzawa Y, Sakamoto W, Baba N, Miyawaki I (2002) Pelagic habitat use of an adult Japanese male loggerhead turtle Caretta caretta examined by the Argos satellite system. Fish Sci 68: 945-947

Hays GC, Luschi P, Papi F, Seppia C, Marsh R (1999) Changes in behaviour during the inter-nesting period and post-nesting migration for Ascension Island green turtles. Mar Ecol Prog Ser 189: 263-273

Hays GC, Åkeson S, Godley BJ, Luschi P, Santidrian P (2001a) The 
implications of location accuracy for the interpretation of satellite-tracking data. Anim Behav 61: 1035-1040

Hays GC, Dray M, Quaife T, Smyth TJ, Mironnet NC, Luschi P, Papi F, Barnsley MJ (2001b). Movements of migrating green turtles in relation to AVHRR derived sea surface temperature. Int $\mathrm{J}$ Remote Sensing 22: 1403-1411

Hays GC, Broderick AC, Godley BJ, Luschi P, Nichols WJ (2003) Satellite telemetry suggests high levels of fishing-induced mortality in marine turtles. Mar Ecol Prog Ser 262: 305-309

Hays GC, Luschi P, Papi F, Seppia G, King RS, Lloyd G, Lovell P (2004) First records of oceanic dive profiles for leatherback turtles, Dermochelys coriacea, indicate behavioural plasticity associated with long-distance migration. Anim Behav 67: 733743

Hilton-Taylor C (2000) 2000 IUCN red list of threatened species. IUCN, Gland, Switzerland and Cambridge, UK, pp 1-61

Horrocks JA, Vermeer LA, Krueger B, Coyne M, Schroeder BA, Balazs $\mathrm{GH}$ (2001) Migration routes and destination characteristics of post-nesting hawksbill turtles satellite-tracked from Barbados, West Indies. Chelonian Conserv Biol 4: 107-114

Hulbert IAR, French J (2001) The accuracy of GPS for wildlife telemetry and habitat mapping. J Appl Ecol 38: 869-878

Jay CV, Garner GW (2002) Performance of a satellite-linked GPS on Pacific walruses (Odobenus resmarus divergens). Polar Biol 25: $235-237$

Keating (1994) An alternative index of satellite telemetry location error. J Wildl Manage 58: 414-421

Luschi P, Hays GC, Papi F (2003a) A review of long-distance movements by marine turtles, and the possible role of ocean currents. OIKOS 103: 293-302

Luschi P, Sale A, Mencacci R, Hughes GR, Lutjeharms JRE, Papi F (2003b) Current of leatherback sea turtles (Dermochelys coriacea ) in the ocean. Proc Royal Soc Lond Ser B 270 (Suppl 2): S129-S132

McConnell BJ, Fedak MA, Lovell P, Hammond PS (1999) Movements and foraging areas of grey seals in the North Sea. J Appl Ecol 36: 573-539
Mendonca MT (1983) Movements and feeding ecology of immature green turtles (Chelonia mydas) in a Florida lagoon. Copeia 1983: 1013-1023

Polovina JJ, Kobayashi DR, Ellis DM, Seki MP, Balazs GH (2000) Turtles on the edge: movement of loggerhead turtles (Caretta caretta) along oceanic fronts in the central North Pacific, 19971998. Fish Oceanog 9: 71-82

Polovina JJ, Balazs GH, Howell EA, Parker DM, Seki MP, Dutton $\mathrm{PH}$ (2004) Forage and migration habitat of loggerhead (Caretta caretta) and olive ridley (Lepidochelys olivacea) sea turtles in the central North Pacific Ocean. Fish Oceanog 13: 36-51

Renaud ML Carpenter JA (1994) Movements and submergence patterns of loggerhead turtles (Caretta caretta) in the Gulf of Mexico determined through satellite telemetry. Bull Mar Sci 55: $1-15$

Renaud ML, Carpenter JA, Williams JA, Manzalla-Tirpak SA (1995) Activities of juvenile green turtles, Chelonia mydas, at a jettied pass in south Texas. Fish Bull 93: 586-593

Rodgers AR, Rempel RS, Abraham KF (1996) A GPS-based telemetry system. Wildl Soc Bull 24: 559-566

Ryan PG, Petersen SL, Peters G, Grémillet D (2004) GPS tracking a marine predator: the effects of precision, resolution and sampling rate on foraging tracks of African Penguins. Mar Biol 145: 215-223

Silverman BW (1986) Density estimation for statistics and data analysis. In "Monographs on Statistics and Applied Probability Vol 26", Chapman \& Hall, London

Seminoff JA, Resendiz A, Nichols WJ (2002) Home range of green turtles Chelonia mydas at a coastal foraging area in the Gulf of California, Mexico. Mar Ecol Prog Ser 242: 253-265

Worton BJ (1987) A review of models of home range for animal movement. Ecol Model 38: 277-298

Worton BJ (1989) Kernel methods for estimating the utilization distribution in home-range studies. Ecology 70: 164-168

(Received February 3, 2005 / Accepted March 18, 2005) 